American Journal of Pharmaceutical Education 2019; 83 (5) Article 6710.

\title{
RESEARCH
}

\section{Cross-cultural Comparison of Pharmacy Students' Attitudes, Knowledge, Practice, and Barriers Regarding Evidence-based Medicine}

\author{
Aya F. Ozaki, PharmD, ${ }^{a}$ Sari Nakagawa, PhD, ${ }^{b}$ Cynthia A. Jackevicius, PharmD, MSc ${ }^{\text {a,c-f }}$ \\ ${ }^{a}$ Western University of Health Sciences, Pomona, California \\ ${ }^{\mathrm{b}}$ Kobe Gakuin University, Hyogo, Japan \\ ${ }^{c}$ VA Greater Los Angeles Healthcare System, Los Angeles, California \\ ${ }^{\mathrm{d}}$ Institute for Clinical Evaluative Sciences, Toronto, Ontario, Canada \\ ${ }^{\mathrm{e}}$ University Health Network, Toronto, Ontario, Canada \\ ${ }^{\mathrm{f}}$ University of Toronto, Toronto, Ontario, Canada
}

Submitted August 9, 2017; accepted December 6, 2017; published June 2019.

Objective. To explore cultural influences on US and Japanese pharmacy students' evidence-based medicine (EBM) attitudes, knowledge, and behavior.

Methods. A cross-sectional study was conducted using a self-administered survey. Senior students in one pharmacy school in the United States and two pharmacy schools in Japan were invited to complete a 33-item survey instrument.

Results. Students in both countries reported having positive attitudes and understanding of EBM concepts. In their self-evaluation, American students rated their current EBM practice, EBM skills, and access to EBM resources higher than Japanese students rated themselves in these areas. The most common barriers to EBM for American students were lack of time (84.5\%), lack of statistical knowledge $(63.9 \%)$, and lack of critical appraisal skills $(53.1 \%)$. The most common barriers to EBM for Japanese students were lack of training (92.6\%), lack of clinical knowledge (90.4\%), and lack of opportunity $(88.8 \%)$.

Conclusion. Although barriers to implementing EBM and confidence levels in using EBM differed between US and Japanese pharmacy students, both cohorts recognized EBM as an important skillset for the pharmacy profession. Culturally specific approaches to teaching EBM to pharmacy students are needed to improve EBM use in practice.

Keywords: evidence-based medicine, pharmacy student, pharmacy education, international comparison, Japan

\section{INTRODUCTION}

Evidence-based medicine (EBM) is a health care concept which integrates the best available research evidence with clinical expertise and patient values and preferences to optimize the care of patients. ${ }^{1,2}$ Evidence-based medicine has been embedded within the medical and health professions for over 20 years. ${ }^{3}$ Today, most medical schools include training in EBM in their curricula, although its implementation is not standardized and multiple methods of teaching EBM have been shown to be effective. ${ }^{4,5}$ Behaviors and attitudes of physicians and medical students have been examined in several studies and have found heterogeneity in their level of knowledge and EBM usage by country and specialty. ${ }^{6-11}$

Corresponding Author: Cynthia A. Jackevicius, Western University of Health Sciences, 309 E. Second St., Pomona, CA 91766. Tel: 909-469-5527. Fax 909-469-5539. E-mail: cjackevicius@westernu.edu
While evidence-based medicine has been adopted into pharmacy practice over the last decade, ${ }^{12}$ little about EBM education in pharmacy has been published in the literature. The role of pharmacists has shifted from dispensing to patient-focused care and clinical decisionmaking. This has led to the emergence of EBM as a new paradigm for pharmacy practice and education. The ability to retrieve, evaluate, and apply medical literature to patient care is a key skill for pharmacists. Many countries around the world are now following the US Doctor of Pharmacy (PharmD) degree model and modifying their curricular structure from a four-year to a sixyear pharmacy education program with enhanced clinical didactic and experiential content in order to meet the goal of being the profession responsible for ensuring optimal medication use. ${ }^{13-15}$

Although the goals for the pharmacy profession to ensure safe and effective medication use for patients may 


\section{American Journal of Pharmaceutical Education 2019; 83 (5) Article 6710.}

be similar among many developed countries, ${ }^{13-15}$ the approaches used to meet these goals might not be the same because of cultural and sociological differences. Different cultures may diverge in several aspects that may influence the pharmacy profession, including: varying levels of public trust in the health care system and health care practitioners; diverse technical and/or clinical roles for pharmacists within the health care system, which may then affect the curriculum requirements of pharmacy schools as they prepare students for these roles.

Specifically, there are distinctly different characteristics between American and Japanese societies that may influence both the pharmacy profession and student pharmacists in training. The United States tends to be a more individualistic society, with individuals commonly being highly confident and taking initiative (self-enhancing motivation), while Japan is a collectivistic society, with individuals commonly very humble and follow rather than lead (self-improving motivation). ${ }^{16-18}$ Culturally suitable approaches to teaching EBM to pharmacy students may be necessary to ensure optimal education in this area.

Given the importance of EBM in informing decisions regarding medication use, EBM is critical to the practice of pharmacy; thus, culturally specific educational methods may be necessary. Research on student pharmacists' knowledge of as well as attitudes and behaviors toward EBM has been limited. Penetration of EBM education in pharmacy also likely differs in different regions of the world, similar to that seen in medicine. ${ }^{6-11}$ The impact of cultural and societal influences on EBM education across the world is poorly understood in general and specifically in pharmacy. Therefore, the purpose of this study was to characterize and compare the knowledge of and attitudes, and behavior of pharmacy students toward EBM in two countries with distinctly different cultures.

\section{METHODS}

We conducted a cross-sectional survey of student pharmacists in the second and fourth years of the PharmD program at Western University of Health Sciences (Pomona, CA), and in the fourth to sixth years of the Bachelor of Pharmacy programs at Toho University (Chiba, Japan), and at Kobe Gakuin University (Kobe, Japan). All students in were invited to participate in either a web-based or a paper-based survey between March and November 2015. Characteristics of the schools and their EBM curricula are shown in Table 1. While the US fouryear PharmD program requires completion of a minimum of two years of prepharmacy undergraduate courses, Japanese students enter the six-year Bachelor of Pharmacy degree program with only a high school education. Experiential education is typically more extensive in US phar- macy programs than in Japanese programs, and even more extensive at WesternU. Experiential education at WesternU occurs as introductory experiences in the first and second years, with more advanced experiences occurring during the third and fourth year for a total of 60 weeks of experiential education. The duration of experiential pharmacy education in Japan is shorter at 22 weeks, and takes place solely in the fifth year of school. In the United States, lectures often include active learning. In contrast, Japanese lectures are more traditional and include only a limited degree of active learning, which may be due in part to the large class sizes.

The data collection tool used in this study was a selfadministered questionnaire consisting of close-ended questions regarding the respondent's attitudes toward EBM, knowledge of and preference to use different evidencebased information sources, and possible barriers to EBM application. The questionnaire was developed based on comprehensive literature review and was adapted from questionnaires used in previous studies in this area. ${ }^{19-22}$ The face and content validity of the questionnaire was confirmed by two EBM experts. The questionnaire was originally in English then translated into Japanese by two native Japanese speakers with back translation to English to compare with the original English questionnaire. The questionnaire included 33 questions: attitudes toward EBM (seven items), general knowledge about EBM (four items), exposure to EBM (three items), usage-practice of EBM (three items), self-evaluated skills (five items), access to EBM resources (five items), future use of EBM (four items), EBM terminology (one item with six terms), and barriers to EBM use (one item with 14 barriers in three categories). Similar to other studies, we included a question with a meaningless, dummy term in order to determine students' accuracy of self-assessed EBM knowledge and their interest in learning new terms. ${ }^{22}$ To measure students' knowledge, attitudes, and perceptions regarding EBM, we used either yes/no responses or responses based on a four-point Likert scale, with anchors tailored to the specific section. For agreement questions, the response options were strongly agree, agree, disagree, and strongly disagree. For frequency questions, the response options were rarely, sometimes, usually, and always. For terminology questions, the response options were can explain to others, know somewhat, want to know, and don't need to know. $^{22}$ Participants were invited to participate in the survey in their classrooms. They were provided with either a web link to the survey sent via email or a paper survey instrument. Email was not routinely used to communicate to students at Kobe Gakuin University, so a paper-based survey was administered. Students completed the survey in class during break time. 


\section{American Journal of Pharmaceutical Education 2019; 83 (5) Article 6710.}

Table 1. Characteristics of Schools and Participants in a Cross-cultural Comparison of Pharmacy Students' Attitudes, Knowledge, Practice, and Barriers Regarding Evidence-Based Medicine

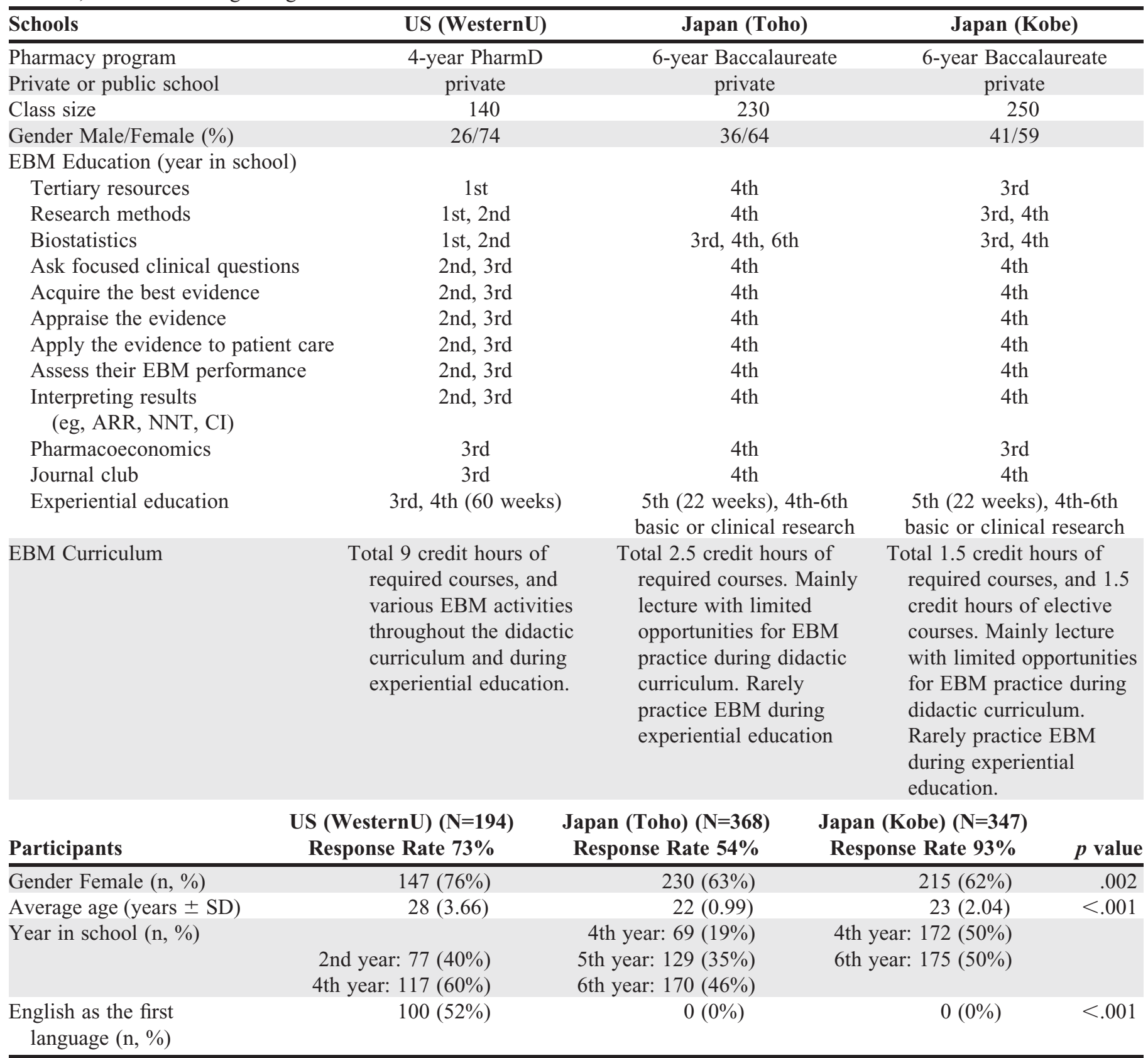

Abbreviations: $\mathrm{ARR}=$ absolute risk reduction, $\mathrm{CI}=$ confidence interval, $\mathrm{EBM}=$ Evidence-Based Medicine, Kobe $=$ Kobe Gakuin University, $\mathrm{NNT}=$ number needed to treat, PharmD $=$ Doctor of Pharmacy, Toho=Toho University, WesternU $=$ Western University of Health Sciences

Descriptive statistics (expressed as percentages) were used to describe categorical data. Means with standard deviations were used to describe continuous data. Responses of strongly agree and agree were combined, as were responses of always and usually, and strongly disagree and disagree. Because responses from the two Japanese schools did not differ and the purpose of our study was to identify differences between the United States and Japan, the Japanese responses were combined. Two-way analysis of variance was used to compare mean differences between groups. Chi-square was used to compare proportions. A $p$ value of $<.05$ was considered significant. Data were analyzed using SAS, version 9.3 (Cary, NC). The study was approved by the Institutional Review Board at Western University of Health Sciences.

\section{RESULTS}

A total of 909 students (response rate, $68.8 \%$ ) from three pharmacy schools participated in the study: 194 


\section{American Journal of Pharmaceutical Education 2019; 83 (5) Article 6710.}

US students in their second or fourth years at Western University of Health Sciences (web-based survey administered, response rate of $73.8 \%$ ), and 368 students in their fourth, fifth, or sixth year at Toho University (web-based survey administered: response rate 53.7\%), and 347 students in their fourth or sixth year at Kobe Gakuin University (paper-based survey, response rate 93.0\%). The paper-based survey administered at Kobe Gakuin University had a higher response rate than did the web-based survey completed by students at the other two schools. The majority of participants in the United States (75.8\%) and Japan (62.2\%) were female. Japanese students were significantly younger than American students (Table 1).

In both countries, the majority of students had positive attitudes toward EBM and reported having an understanding of EBM concepts (Table 2). The majority of students in both the US and Japanese groups agreed that EBM improves the quality of decision making for patient care $(97.9 \%$ vs $94.7 \%)$ and is important for the pharmacy profession (95.9\% vs $96.8 \%$ ). Only one negative attitude regarding EBM use, the overwhelming amount of evidence, was agreed to by both US $(59.8 \%)$ and Japanese $(73.8 \%)$ students. Although EBM use had been emphasized within the respective pharmacy curricula, the majority of students in both countries had not observed pharmacists or medical professionals using EBM frequently in practice. American students evaluated their current EBM practice $(84.5 \%$ vs $64.1 \%$ ), as well as their own EBM skills and access to EBM resources significantly higher than the Japanese students did. There were no statistically significant differences between the groups regarding their intentions to use EBM in future practice (Table 2).

The survey examined pharmacy students' knowledge of common EBM terms. The percentages of students in the US and Japan, respectively, that indicated at least some understanding of common EBM terms were as follows: $99.0 \%$ vs $47.8 \%$ for "number needed to treat," $99.0 \%$ vs $72.0 \%$ for "publication bias," $99.0 \%$ vs $60.2 \%$ for "confidence interval," $97.4 \%$ vs $82.6 \%$ for meta-analysis, and $93.8 \%$ vs $92.0 \%$ for "odds ratio." The term "fixed event rate" was a meaningless dummy term. In Japan, $77.9 \%$ of students responded "want to know" and $17.7 \%$ reported either "can explain to others" or "know somewhat." However, in the United States, only $29.4 \%$ of students reported "want to know," while $69.6 \%$ reported that they "can explain to others" or "know somewhat."

The most common barriers to use of EBM among US students were lack of time $(84.5 \%)$, statistical knowledge (63.9\%), and critical appraisal skills
$(53.1 \%)$, and for Japanese students, lack of training $(92.6 \%)$, clinical knowledge $(90.4 \%)$, and opportunity (88.8\%) (Figure 1). There were 13 barriers identified by $>50 \%$ of Japanese students, while only three barriers identified by $>50 \%$ of US students. Time was the only barrier that Japanese students $(59.9 \%)$ identified less frequently than American students $(84.5 \%$. $p<.001$ ).

Barriers to EBM use were categorized into three groups: skills, environment, and attitudes (with seven items in skills, five items in environment, and two items in attitudes) (Figure 2). The mean number of skill barriers identified by Japanese students was $5.7(\mathrm{SD}=1.7)$ out of 7 items ( $81.6 \%$ of all possible skills barriers), while US students identified $2.6(\mathrm{SD}=2.2)$ out of 7 items $(36.9 \%$ of all possible skills barriers $)(p<.001)$. The mean number of environment barriers identified by Japanese students was $3.5(\mathrm{SD}=1.2)$ out of 5 items $(69.2 \%$ of all possible environment barriers), while US students identified 1.7 $(\mathrm{SD}=1.8)$ items $(33.4 \%)(p<.001)$. The mean number of attitudes barriers identified by Japanese students was $1.2(\mathrm{SD}=0.7)$ out of 2 items $(59.5 \%$ of all possible attitudes barriers), while US students identified 1.2 $(\mathrm{SD}=0.7)$ out of 2 items (61.5\% of all possible attitudes barriers) $(p=.49)$. Two questions within the attitude category showed different patterns, which may explain the lack of difference for the attitude category overall. Time was identified as a barrier more often by American students, while interest was identified as a barrier more often by Japanese students.

\section{DISCUSSION}

The findings from this study indicate that student pharmacists in both countries value EBM despite different educational structures. Pharmacy students in both countries had positive attitudes toward EBM. This finding was consistent with studies conducted with other medical professionals and students..$^{8-11,22}$ There is increasing awareness of and perceived need to incorporate EBM into pharmacy program curricula in both countries. ${ }^{12,23,24}$

The majority of students in both countries reported at least some understanding of common EBM terms (4 terms out of 5 in Japan, and 5 terms out of 5 in the United States). "Number needed to treat (NNT)" for Japanese students was the least understood term (47.8\%), whereas it was the best understood term among US students $(99.0 \%)$. In contrast, "odds ratio" was the most understood term among Japanese students $(92.0 \%)$, while it was the lowest for American students (93.8\%). Similarly, in a study conducted among Japanese resident physicians, the highest knowledge score was also for odds ratio and the lowest 


\section{American Journal of Pharmaceutical Education 2019; 83 (5) Article 6710.}

Table 2. US and Japanese Pharmacy Student's Attitudes, Knowledge, Usage-Practice, Exposure, Skills, Access, and Future Use Regarding Evidence-based Medicine

\begin{tabular}{|c|c|c|c|}
\hline & US (\%) & Japan (\%) & $p$ value \\
\hline Attitudes & $\begin{array}{l}\text { Strongly Agree }+ \\
\text { Agree }\end{array}$ & $\begin{array}{l}\text { Strongly Agree }+ \\
\text { Agree }\end{array}$ & \\
\hline EBM improves the quality of decision-making & 98 & 95 & .05 \\
\hline $\begin{array}{l}\text { Pharmacists have a responsibility to refer to evidence to make } \\
\text { recommendations }\end{array}$ & 97 & 94 & .05 \\
\hline Pharmacists have a responsibility to keep updating their knowledge & 99 & 98 & .27 \\
\hline EBM is an important skill for pharmacists & 96 & 97 & .54 \\
\hline Pharmacists, in general, should not practice EBM & 5 & 9 & .11 \\
\hline The amount of evidence is overwhelming & 60 & 74 & $<.001$ \\
\hline The adoption of EBM places an unreasonable demand on pharmacists & 22 & 9 & $<.001$ \\
\hline General Knowledge & $\begin{array}{l}\text { Strongly Agree }+ \\
\text { Agree }\end{array}$ & $\begin{array}{l}\text { Strongly Agree }+ \\
\text { Agree }\end{array}$ & \\
\hline EBM requires effective search skills & 97 & 98 & .58 \\
\hline Critically appraised evidence should be appropriately applied & 98 & 96 & 12 \\
\hline EBM does NOT take into account patients' preferences & 35 & 12 & $<.001$ \\
\hline EBM is cook-book medicine that disregards clinical experience & 13 & 19 & .05 \\
\hline Exposure & Always + usually & Always + usually & \\
\hline How frequently do you see pharmacists using EBM? & 32 & 21 & .001 \\
\hline How frequently do you see other medical professionals using EBM? & 28 & 23 & .20 \\
\hline Professors emphasize the importance of EBM use during lectures & 95 & 76 & $<.001$ \\
\hline Usage-practice & $\begin{array}{l}\text { Strongly Agree }+ \\
\text { Agree }\end{array}$ & $\begin{array}{l}\text { Strongly Agree }+ \\
\text { Agree }\end{array}$ & \\
\hline The practice of EBM is a routine part of my learning & 85 & 64 & $<.001$ \\
\hline The practice of EBM has changed the way I learn & 86 & 31 & $<.001$ \\
\hline I personally appreciate the advantages of practicing EBM & 96 & 90 & 007 \\
\hline Self-evaluated skills (5As) & $\begin{array}{l}\text { Strongly Agree + } \\
\text { Agree }\end{array}$ & $\begin{array}{l}\text { Strongly Agree }+ \\
\text { Agree }\end{array}$ & \\
\hline I can formulate a focused clinical question & 98 & 64 & $<.001$ \\
\hline I can effectively search & 94 & 35 & $<.001$ \\
\hline I can critically appraise & 91 & 28 & $<.001$ \\
\hline I can appropriately apply & 94 & 35 & $<.001$ \\
\hline I can assess my own EBM skills & 85 & 28 & $<.001$ \\
\hline Access (How frequently do you access) & Always + usually & Always + usually & \\
\hline Textbook & 28 & 18 & .002 \\
\hline Any data source & 82 & 13 & $<.001$ \\
\hline Internet & 62 & 39 & $<.001$ \\
\hline Original research papers & 38 & 11 & $<.001$ \\
\hline UpToDate, ACP Journal Club or Clinical Evidence & 78 & 4 & $<.001$ \\
\hline Future use & $\begin{array}{l}\text { Strongly Agree }+ \\
\text { Agree }\end{array}$ & $\begin{array}{l}\text { Strongly Agree }+ \\
\text { Agree }\end{array}$ & \\
\hline EBM will be useful in my future practice & 97 & 98 & .50 \\
\hline I support lifelong learning & 94 & 91 & 14 \\
\hline I am willing to practice EBM in the future & 92 & 95 & .18 \\
\hline EBM should be an integral part of the pharmacy curriculum & 95 & 92 & .24 \\
\hline
\end{tabular}

Abbreviations: $\mathrm{ACP}=$ American College of Physician, $\mathrm{EBM}=$ evidence-based medicine 
American Journal of Pharmaceutical Education 2019; 83 (5) Article 6710.
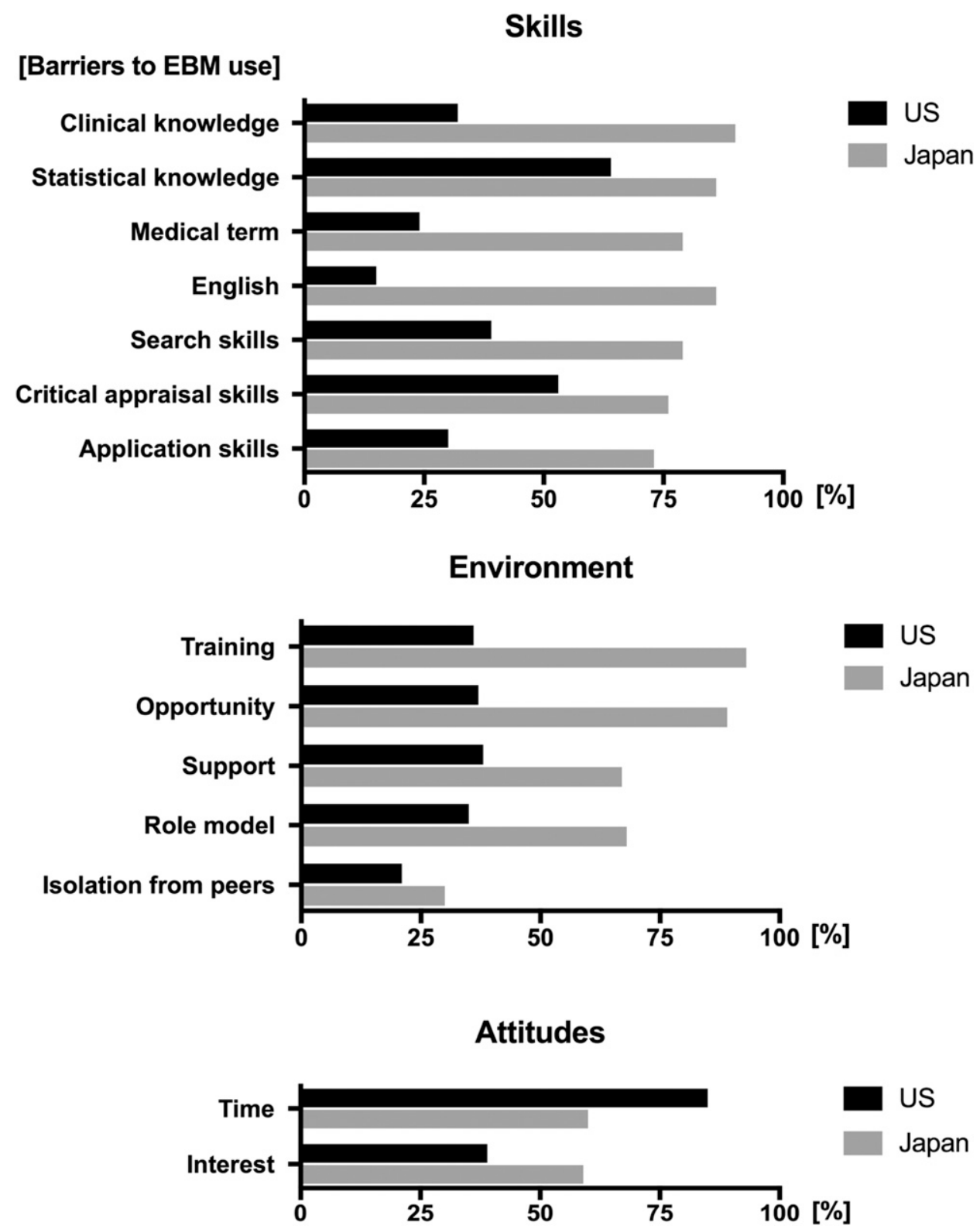

Figure 1. Proportion of Students' Reporting Barriers to EBM Use by Skills, Environment, and Attitudes

score was for NNT. ${ }^{8}$ Japanese students and practitioners are more familiar with statistical terms than EBM-specific terms. This may be the result of greater exposure to basic sciences and traditional research concepts in Japanese pharmacy schools than in US schools. This is reflected in the compositional differences in pharmacy faculty members between the pharmacy schools examined in the two countries. In our study, the proportion of basic sciences to clinical faculty members in Japan was much higher ( $>85 \%$ are basic scientists) than that in the US ( $<40 \%$ are basic scientists). In addition, Japanese students have a lengthy, mandatory research course, which occurs in the fourth through the sixth years, during which students conduct either clinical or basic science research. Therefore, Japanese students have more exposure to basic science and traditional research concepts. In a metaanalysis of physicians from 18 different countries, $83 \%$ of physicians indicated their understanding of NNT, ${ }^{22}$ while $74 \%-75 \%$ of pharmacists in the United States and Australia understand NNT. ${ }^{25,26}$ While common EBM terms have been penetrating the health profession lexicon around the world, American pharmacy students appear to have greater recognition of the terms than do Japanese pharmacy students.

We included the meaningless dummy term "fixed event rate" to determine students' accuracy of self- 


\section{American Journal of Pharmaceutical Education 2019; 83 (5) Article 6710.}

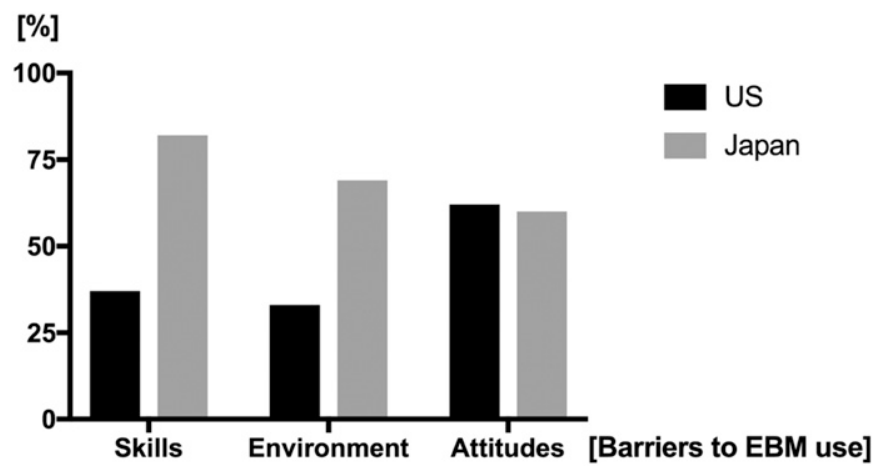

Figure 2. Proportion of Students' Reporting Barriers to EBM Use According to Three Categories

assessed knowledge and their interest in learning new terms. The majority of Japanese students $(77.9 \%)$ reported "wanted to know" and only $4.4 \%$ reported "no need to know," while the majority of US students $(69.6 \%)$ indicated their understanding of the dummy term, either unconsciously or consciously, which suggests a possible bias of socially desirable responding (SDR). Paulhus refined SDR into two distinct factors: selfdeceptive enhancement (SDE) and impression management (IM). ${ }^{27}$ Studies show that American students have higher SDE than Japanese students, whereas Japanese have higher IM than American students. ${ }^{28}$ Self-deceptive enhancement is part of SDR and reflects an overly positive presentation of oneself unconsciously, in other words, positively biased self-perceptions. This may have affected our results regarding American students' perception of their skills, knowledge, and barriers to EBM use. Possible reasons that Japanese students may not have exhibited SDR is that unfamiliarity with EBM may be common among pharmacy students; hence, they could express their uncertainty without feeling judged. Furthermore, Japanese tend to be self-critical by nature and that may influence their response to self-perception questions. Although we cannot conclude the existence of SDR, the erroneous answer from US students regarding the dummy term was notable. In contrast, Japanese students recognized their unfamiliarity with the dummy term despite having less understanding of common EBM terms as compared to US students.

Although students in both countries recognized the value of EBM and possessed general EBM knowledge, there was low self-reported usage of EBM resources by student pharmacists in both countries. Other studies have found similar results among medical residents. ${ }^{6,9-11}$ In Japan, where EBM skills are taught in lectures and there are only limited opportunities to practice EBM, the majority $(92.6 \%)$ of students identified lack of training as a barrier to use of EBM. In contrast, only $36 \%$ of American students identified lack of training as a barrier to using EBM. While the six-year pharmacy program that started in Japan in 2006 expanded clinical training compared with the previous four-year program, the clinical curriculum may still not be fully developed. Compared to the United States, the Japanese program also provides fewer didactic credit hours for EBM, limited active learning of EBM, a shorter length of experiential education than in the United States, and limited EBM application during experiential education. Because clinical services provided by pharmacists in Japan are more limited than those provided in the United States, Japanese students also may have less opportunity to learn EBM skills from preceptors. Furthermore, because pharmacy technicians do not exist in Japan, additional time must be taken in the pharmacy curriculum to teach technical skills. This may reduce time available for clinical training, especially during experiential education.

In contrast, among the US school surveyed, where EBM training and presentations are required throughout didactic courses and experiential education, all environmental barriers were identified by $<50 \%$ of American students. Nevertheless, EBM use in the United States is still suboptimal. Although several studies have demonstrated the effectiveness of EBM training via a one-day workshop, journal club, monograph assignment, or computer- or lecture-based instructions in increasing EBM knowledge in students and practitioners, ${ }^{29-34}$ the acquired knowledge did not equate to an increase in their actual use of EBM. Although there is an overwhelming emphasis on the importance of EBM, its implementation into practice remains suboptimal. ${ }^{38-40}$ The ever-expanding base of medical knowledge and research evidence, along with increasing complexity of disease management of patients with multiple co-morbidities in aging societies presents challenges for widespread EBM implementation. As others have found, EBM curricula need to be integrated with educational interventions that change behavior in learners to establish a new routine of actual EBM use. ${ }^{35-37}$

Our results show that there were no significant differences between US and Japanese pharmacy students in attitudes about and willingness to use EBM in the future. Students from both countries indicated they did not frequently observe pharmacists or other medical professionals using EBM, which further confirms the reported lack of implementation in practice. The majority (68.0\%) of Japanese students identified that lack of a role model was a barrier to EBM use, while fewer (35.1\%) American students reported this. As stated earlier, Japan is a collective society as compared with the individualistic society 


\section{American Journal of Pharmaceutical Education 2019; 83 (5) Article 6710.}

found in the United States. Thus, Japanese organizations have more resistance to change, and the Japanese people typically prefer to follow others rather than lead. ${ }^{17,18}$ This is particularly true in medicine, where decision-making historically has been hierarchy-based or authority or "expert"-based medicine. ${ }^{41,42}$ In such an environment, students may not be comfortable using EBM without the influence and encouragement of a role model. In contrast, in an individualistic society like the United States, pharmacy students rely less on role models when entering into new fields and may be more comfortable with taking initiative in implementing EBM. Several studies emphasize the importance of educating instructors themselves as the impact of role models is strong. ${ }^{43}$ Despite a lack of role models in Japan, more than $90 \%$ of Japanese pharmacy students reported a willingness to use EBM in the future, and nearly all students indicated that they felt EBM would be useful to their practice. This may represent an important area of opportunity in Japan, where the introduction of more role models might facilitate EBM use by students who are willing and ready, as well as encourage students to become role models themselves.

Nearly $90 \%$ of American students reported confidence in their EBM skills. In addition, all survey terms were reported to be understood by more than $90 \%$ of American students, and the majority of skills were not identified as a barrier to their use of EBM. In contrast, the majority of Japanese students evaluated their own skills as insufficient and their proficiency in all skills as posing a barrier to implementing EBM. Because of cultural differences in self-evaluation and SDR, students' reported or self-perceived level of confidence may not reflect their actual skills and confidence. In contrast to the self-confidence reflected in the American pharmacy students' self-evaluation, one meta-analysis reported that the majority of physicians from 18 different countries considered their evidence-based practice skills to be insufficient. ${ }^{22}$ As compared to practitioners in the United States, US pharmacy students in this study may have had poor insight or overly evaluated their skills, which may have a negative impact on their EBM use in the future. On the other hand, these students may have had better EBM training, as EBM has been adopted to a greater extent in the US pharmacy curriculum in recent years. Also, practitioners may be more aware of the difficulty of EBM implementation than students who lack practical experience.

The fact that the "number needed to read" (NNR) for identifying clinically relevant studies published in one journal of emergency medicine was 26.7, shows that searching for evidence is not an easy task in practice. ${ }^{44}$ Despite the reality of NNR, few students in the United
States identified concerns for EBM searching skills. American and Japanese students may have different perspectives on the role of barriers. One study showed that Americans work longer if they succeed at the first task while Japanese individuals work longer if they fail. ${ }^{16} \mathrm{Jap}$ anese have a "self-improving motivation," ie, trying to prevent failure, while Americans have a "self-enhancing motivation," ie, focusing on their strengths. ${ }^{16}$ Also, American students may not be willing to admit their uncertainty. ${ }^{45}$ While capitalizing and building on strengths is helpful, in order to continue learning essential EBM skills, accurate self-assessment capabilities are critical. In contrast, Japanese students may focus excessively on uncertainty, which may prevent them from building confidence. Repetitive training tends to result in better learning outcomes than single training sessions. ${ }^{46}$ Especially for those with a tendency of self-improving motivation, providing repetitive training, or engaging in repetitive practices may improve their skills and help them to gain confidence. The methods for gaining self-confidence in Japan may differ from those in the United States, and added emphasis on adequate training and support may be necessary.

There are some limitations to our study. First, this was a self-administered survey that examined selfperceptions, not actual knowledge. Future research should assess EBM knowledge using validated questionnaires that focus on outcomes rather than simply perceptions. $^{20,21}$ Second, our survey instrument was not prospectively tested for validity; however, it was tested for face and content validity. Future studies should test for validity in different populations. Third, as we administered the survey at only one or two schools in each country, the results may not represent all of the schools in each of the countries, which limits the external validity of our findings. Future research should survey a larger number of institutions in each country. Fourth, as is common to surveys, the responses represent participants' self-assessment. And there is a possible non-response bias as all those who were invited did not participate in the survey. Those who responded may have had a different perspective than those who did not respond. Finally, we only evaluated student pharmacists in their later years of education, after a greater degree of exposure to EBM education. Student pharmacists' perceptions may be different earlier in their pharmacy education, and future studies should examine students at this time point.

\section{CONCLUSION}

Substantial awareness of EBM was identified within this cohort of US and Japanese pharmacy students. 


\section{American Journal of Pharmaceutical Education 2019; 83 (5) Article 6710.}

Students in both countries understood the importance of EBM and reported their willingness to use EBM. However, barriers faced and level of confidence differed between the two cohorts. Lack of EBM role models may hinder optimal student practice, particularly in Japan. Self-assessment is critical for students to continue developing their EBM skills. Culturally specific approaches may be needed in order to improve EBM use and selfdirected learning behaviors.

\section{ACKNOWLEDGMENTS}

Aya F. Ozaki was funded in part by the Summer Research Fellowship Program, Student Research Grant from Western University of Health Sciences. The authors would like to express their gratitude to Dr. Hikaru Tanaka and Mr. Kousuke Katayama for conducting surveys, and Dr. Kazuhiro Matsuo for providing his insight regarding EBM curriculum at Toho University, Japan.

\section{REFERENCES}

1. Sackett DL, Rosenberg WM, Gray JA, Haynes RB, Richardson WS. Evidence based medicine: what it is and what it isn't. BMJ. 1996;312(7023):71-72.

2. Guyatt GH, Rennie D. Users' Guides to the Medical Literature: A Manual of Evidence-Based Clinical Practice (first ed.). Chicago: American Medical Association Press. 2002;90(4).

3. Evidence-Based Medicine Working Group. Evidence-based medicine. A new approach to teaching the practice of medicine. JAMA. 1992;268(17):2420-2425.

4. Maggio LA, Tannery NH, Chen HC, Ten Cate O, O'Brien B. Evidence-based medicine training in undergraduate medical education: a review and critique of the literature published 2006-2011. Acad Med. 2013;88(7):1022-1028.

5. Ilic D, Maloney S. Methods of teaching medical trainees evidence-based medicine: a systematic review. Med Educ. 2014;48(2):124-135.

6. Hisham R, Ng CJ, Liew SM, Hamzah N, Ho GJ. Why is there variation in the practice of evidence-based medicine in primary care? A qualitative study. BMJ Open. 2016;6(3):e010565.

7. Bednarczyk J, Pauls M, Fridfinnson J, Weldon E. Characteristics of evidence-based medicine training in Royal College of Physicians and Surgeons of Canada emergency medicine residencies - a national survey of program directors. BMC Med Educ. 2014;14:57.

8. Risahmawati RR, Emura SS, Nishi TT, Koizumi SS. Japanese resident physicians' attitudes, knowledge, and perceived barriers on the practice of evidence based medicine: a Survey. BMC Res Notes. 2011;4:374.

9. Anuradha C, Jacob KS, Shyamkumar NK, Sridhar G. Evidencebased practice in radiology: knowledge, attitude and perceived barriers to practice among residents in radiology. Eur J Radiol. 2013:82(5):894-897.

10. Al Omari M, Khader Y, Jadallah K, Dauod AS, Al-Shdifat AA, Khasawneh NM. Evidence-based medicine among hospital doctors in Jordan: awareness, attitude and practice. J Eval Clin Pract.

2009;15(6):1137-1141.

11. Ghahremanfard F, Nassaji M, Mirmohammadkhani M, et al. Knowledge and attitude toward evidence-based medicine among medical students in Semnan, Iran. J Evid Based Med. 2014;7(1):32-37.
12. American College of Clinical Pharmacy. The definition of clinical pharmacy. Pharmacotherapy. 2008;28(6):816-817.

13. Dolder C, Nakagawa S, Sakamaki A, Supernaw R. Changes in Japanese pharmacy education and practice. Am J Health Syst Pharm. 2008;65(3):201-202.

14. Jiang JH, Liu Y, Wang YJ, et al. Clinical pharmacy education in China. Am J Pharm Educ. 2011;75(3):Article 57.

15. Marriott JL, Nation RL, Roller L, et al. Pharmacy education in the context of Australian practice. Am J Pharm Educ.

2008;72(6):Article 131.

16. Heine SJ, Lehman DR, Ide E, et al. Divergent consequences of success and failure in japan and north america: an investigation of self-improving motivations and malleable selves. J Pers Soc Psychol. 2001;81(4):599-615.

17. Roland G. Understanding institutional change: fast-moving and slow-moving institutions. St Comp Int. 2004;38(4):109-131.

18. Herbig P, Jacobs L. The Future of Japanese Innovation: Leader or Follower? Business Forum. 1999;24:4-8.

19. McColl A, Smith H, White P, Field J. General practitioner's perceptions of the route to evidence based medicine: a questionnaire survey. BMJ. 1998;316(7128):361-365.

20. Ramos KD, Schafer S, Tracz SM. Validation of the Fresno test of competence in evidence based medicine. BMJ. 2003;326(7384): 319-321.

21. Fritsche L, Greenhalgh T, Falck-Ytter Y, Neumayer HH, Kunz R. Do short courses in evidence-based medicine improve knowledge and skills? Validation of Berlin Questionnaire and before and after study of courses in evidence-based medicine. BMJ 2002;325(7376): 1338-1341.

22. Ubbink DT, Guyatt GH, Vermeulen H. Framework of policy recommendations for implementation of evidence-based practice: a systematic scoping review. BMJ Open. 2013;3(1):e001881.

23. 2016 Accreditation Standards and Key Elements for the Professional Program in Pharmacy Leading to the Doctor of Pharmacy Degree. Accreditation Council for Pharmacy Education; 2015.

24. Ministry of Education, Japan; http://www.mext.go.jp/b_menu/ shingi/chousa/koutou/039/attach/1334995.htm. Accessed December $16,2016$.

25. Burkiewicz JS, Zgarrick DP. Evidence-based practice by pharmacists: utilization and barriers. Ann Pharmacother. 2005;39 (7-8):1214-1219.

26. Peterson GM, Jackson SL, Fitzmaurice KD, Gee PR. Attitudes of Australian pharmacists towards practice-based research. J Clin Pharm Ther. 2009;34(4):397-405.

27. Paulhus DL. Two-component models of socially desirable responding. J Pers Soc Psychol. 1984;46(3):598-609.

28. Chung JM. The contribution of self-deceptive enhancement to display rules in the United States and Japan. Asian J Soc Psychol. 2012;15(1):69-75.

29. Bookstaver PB, Rudisill CN, Bickely RA, et al. An evidencebased medicine elective course to improve student performance in advanced pharmacy practice experiences. Am J Pharm Educ. 2011;75(1):Article 9.

30. Arif SA, Gim S, Nogid Am Shah B. Journal clubs during advanced pharmacy practice experiences to teach literatureevaluation skills. Am J Pharm Educ. 2012;76(5):Article 88. 31. Law AV, Jackevicius CA, Bounthavong M. A monograph assignment as an integrative application of evidence-based medicine and pharmacoeconomic principles. Am J Pharm Educ. 2011;75(1): Article 1. 


\section{American Journal of Pharmaceutical Education 2019; 83 (5) Article 6710.}

32. Wittman D, Kovera C, Sullivan M, Rumore MM. Incorporating a drug information consult into a pharmacy practice course to build literature search and evaluation skills through a 3 -stage model. $J$ Pharm Pract. 2017;30(3):306-312.

33. Dawn S, Dominguez KD, Troutman WG, Bond R, Cone C. Instructional scaffolding to improve students' skills in evaluating clinical literature. Am J Pharm Educ. 2011;75(4):Article 62. 34. Longyhore D, Ference K, Nanstiel B. An elective course in information mastery. Am J Pharm Educ. 2011;75(2):Article 20. 35. te Pas E, Wieringa-de Waard M, de Ruijter W, van Dijk N. Learning results of GP trainers in a blended learning course on EBM: a cohort study. BMC Med Educ. 2015;15:104.

36. Shuval K, Berkovits E, Netzer D, et al. Evaluating the impact of an evidence-based medicine educational intervention on primary care doctors' attitudes, knowledge and clinical behaviour: a controlled trial and before and after study. J Eval Clin Pract. 2007;13(4):581-598. 37. McCluskey A, Lovarini M. Providing education on evidencebased practice improved knowledge but did not change behaviour: a before and after study. BMC Med Educ. 2005;5:40.

38. Rao RH. Perspectives in medical education. Reforming medical education to change healthcare practice in Japan. Keio J Med. 2006;55(4):141-148.

39. Greenhalgh T, Howick J, Maskrey N. Evidence based medicine: a movement in crisis? BMJ. 2014;348:g3725.
40. Caspi O, McKnight P, Kruse L, Cunningham V, Figueredo AJ, Sechrest L. Evidence-based medicine: discrepancy between perceived competence and actual performance among graduating medical students. Med Teach. 2006;28(4):318-325.

41. Yokota T, Kojima S, Yamauchi H, Hatori M. Evidence-based medicine in Japan. Lancet. 2005;366(9480):122.

42. Kobayashi H, Pian-Smith M, Sato M, Sawa R, Takeshita T, Raemer D. A cross-cultural survey of residents' perceived barriers in questioning/challenging authority. Qual Saf Health Care. 2006;15(4):277-283.

43. Jochemsen-van der Leeuw HG, van Dijk N, van Etten-Jamaludin FS, Wieringa-da Waard M. The attributes of the clinical trainer as a role model: a systematic review. Acad Med. 2013;88(1):26-34.

44. Worster A, Haynes RB. How do I find a point-of-care answer to my clinical question? CJEM. 2012;14(1):31-35.

45. Maggio LA, ten Cate O, Chen HC, Irby DM, O'Brien BC. Challenges to learning evidence-based medicine and educational approaches to meet these challenges: a qualitative study of selected EBM curricula in U.S. and Canadian medical schools. Acad Med. 2016;91(1):101-106.

46. Bluestone J, Johnson P, Fullerton J, Carr C, Alderman J, BonTempo J. Effective in-service training design and delivery: evidence from an integrative literature review. Hum Resour Health. 2013;11:51. 